\title{
VÍCIOS INTELECTUAIS, MOTIVAÇÃO E RESPONSABILIDADE
}

\section{Bruno Tenório Coelho ${ }^{1}$}

\begin{abstract}
RESUMO
Neste artigo argumento a favor de um pluralismo acerca dos vícios intelectuais. Na primeira seção apresento o obstrucionismo, que define os vícios intelectuais como obstáculos que impedem ou limitam a obtenção de conhecimento. Em seguida, descrevo uma segunda proposta, a qual argumenta que os vícios intelectuais resultam de motivações não instrumentais opostas aos bens epistêmicos. Argumento que a abordagem redutiva não é bemsucedida. Há casos de vícios intelectuais não resultam de uma má motivação. Após apresentar e discutir o obstrucionismo e a abordagem motivacional, considero uma recente preocupação, segundo a qual há um problema de responsabilidade na epistemologia dos vícios.
\end{abstract}

Palavras-chave: Vícios Intelectuais. Epistemologia das Vícios. Motivação. Responsabilidade.

\begin{abstract}
In this paper, I argue for pluralism about intellectual vices. In the first section, I present obstructionism, that defines intellectual vices as obstacles that prevent or limit the acquisition of knowledge. Next, I describe A. Tanesini's (2019) proposal, who argues that intellectual vices result from a non-instrumental motivation to oppose epistemic goods. I argue that Tanesini's reductive approach is unsuccessful. There are cases of intellectual vices that are not the result of bad motivation. After presenting and discussing obstructionism and the motivational approach, I consider a recent concern, according to which there is a problem of responsibility in vice epistemology.
\end{abstract}

Keywords: Intellectual Vices. Vice Epistemology. Motivation. Responsibility.

\footnotetext{
${ }^{1}$ Doutorando em Filosofia pela UFBA. E-mail: frlsba@gmail.com.
} 


\section{Introdução}

A epistemologia das últimas duas décadas difere em larga medida da epistemologia desenvolvida no final do século XX. Questões acerca da performance epistêmica dos agentes se tornaram centrais, complementando a preocupação com a análise de conceitos fundamentais, como o de conhecimento e justificação. Graças ao trabalho de filósofos e filósofas como E. Sosa (2007, 2009) e Zagzebski (1996), há atualmente uma grande preocupação com a agência epistêmica, ou seja, com aqueles aspectos relevantes na consideração dos agentes no interior de uma investigação. Mais particularmente, busca-se saber o que torna uma investigação ou uma pessoa virtuosa epistemicamente. A epistemologia das virtudes é atualmente um campo estabelecido da epistemologia que estuda os traços de caráter, motivações e atitudes que fundamentam a vida epistêmica das pessoas, os quais nos permitem alcançar bons fins e realizar bons atos (AXTELL, 1999; SOSA, 2007). Nesta abordagem, além de se tentar definir precisamente o que é uma virtude intelectual, estuda-se as diferentes virtudes intelectuais como a humildade intelectual e a abertura de espírito. Mais recentemente, observa-se uma grande preocupação com a contraparte das virtudes epistêmicas: os vícios intelectuais. A epistemologia dos vícios, investiga os vícios intelectuais ou epistêmicos². Uma lista mínima de vícios intelectuais irá incluir: "orgulho intelectual, negligência, preguiça, covardia, conformidade, despreocupação, rigidez, preconceito, pensamento ilusório, mente fechada, insensibilidade ao detalhe, ser obtuso, e falta de rigor" (ZAGZEBSKI, 1996, p. 152). Esta lista não é exaustiva. Busca dar uma ideia inicial dos tipos de atitudes, traços de caráter e modos de pensar que caracterizam os vícios. Deve-se destacar, adicionalmente, que não há uma maneira consensual de definir os vícios intelectuais. Irei avaliar ao longo do texto duas propostas: o obstrucionismo e uma proposta baseada em motivações.

Algumas questões que guiam o debate e podem ser levantadas quanto aos vícios intelectuais incluem: Qual a natureza dos vícios intelectuais? Pode-se fornecer um aspecto fundamental que caracterize os vícios ou eles têm origens distintas? As motivações são componentes centrais na especifi-

\footnotetext{
${ }^{2}$ Utilizarei os termos "vícios intelectuais" e "vícios epistêmicos" indistintamente.
} 
cação dos vícios intelectuais? Em que sentido estes vícios são repreensíveis? Pode-se culpar as pessoas por possuírem estes vícios ou haverá casos onde a culpabilidade é imprópria? Como entender a explicação fornecida pelos epistemólogos dos vícios em comparação com outras explicações, por exemplo, envolvendo vieses cognitivos? Pode-se fornecer uma taxonomia minimamente aceitável dos vícios intelectuais? Por fim, reconhecendo que estas atitudes geram consequências negativas, há medidas que podem ser adotadas pela generalidade das pessoas, no intuito de mitigar o impacto negativo dos vícios intelectuais? Todas estas questões são estudadas neste âmbito de investigação.

Das duas propostas a serem consideradas, a primeira, chamada de obstrucionismo, foi desenvolvida por Q. Cassam (2016, 2019). Segundo ele, os vícios intelectuais devem ser entendidos em um sentido plural, ou seja, há diversos tipos de vícios. Alguns podem ser caracterizados como atitudes adotadas pelo agente. Outros são melhor compreendidos como traços de caráter, aspectos profundos do indivíduo que requerem um esforço maior em sua modificação. E há ainda uma terceira categoria, os modos de pensar. Esta proposta conflita com uma caracterização distinta dos vícios intelectuais, promovida por A. Tanesini (2018). Segundo ela, os vícios intelectuais podem ser definidos a partir das motivações não-instrumentais para opor, antagonizar ou evitar coisas que são epistemicamente boas. Nesta acepção, pode-se identificar na generalidade das manifestações de atitudes viciosas um componente motivacional. Irei apresentar as duas propostas, e argumentar que o obstrucionismo é mais plausível.

$\mathrm{O}$ artigo estrutura-se da seguinte forma. Na primeira seção apresento o obstrucionismo. Menciono alguns exemplos paradigmáticos utilizados para caracterizar os vícios intelectuais, como a decisão do governo americano de invadir o Iraque precipitadamente em 2003. Posteriormente, apresento a objeção de A. Tanesini (2018) ao obstrucionismo. Descrevo os argumentos a favor de sua proposta rival. Seu argumento centra-se em uma distinção entre razões explicativas para crenças e ações, e razões explicativas para motivações. Segundo ela, esta distinção no permitir compreender melhor o papel central das motivações na definição dos vícios intelectuais. Irei argumentar que seu argumento é falho: há casos claros onde a atitude viciosa não resulta 
de motivações não-instrumentais. A resposta não questiona, no entanto, uma prática comum das relações humanas: a atribuição de responsabilidade epistêmica e moral. A questão central, a ser avaliada na última parte do texto, resulta de uma preocupação recente levantada por H. Battaly (2019) quanto a atribuição de responsabilidade. Segundo ela, a epistemologia dos vícios possui um problema de responsabilidade. Sua preocupação advém de alguns casos intrigantes onde a pessoa é supostamente responsável por algo que não está em seu controle. Discuto um caso específico de viés implícito fornecido por Battaly e argumento que este caso pode ser explicado pelo obstrucionismo. Apresento também uma recente acomodação feita por Tanesini (2020) do dilema avançado por Battaly.

\section{Vícios Epistêmicos: obstrucionismo}

A alguns anos atrás, Harry Frankfurt defendeu uma distinção entre "falar merda" e mentir (FRANKFURT, 2005). Mentir, segundo ele, consiste em apresentar uma informação falsa deliberadamente, enquanto falar merda resulta de um descaso pela verdade. Em ambos os casos, Frankfurt argumenta, a pessoa é passível de culpa e responsabilidade moral, ainda que intuitivamente o caso da mentira nos pareça mais grave. Utilizando o vocabulário da epistemologia dos vícios, falar merda resulta da indiferença ou descaso epistêmico, onde a pessoa que o exibe não se importa com a verdade (CASSAM, 2018). Em geral, a pessoa tem outros valores, não-epistêmicos, que o levam a esta atitude viciosa. Não se importar com a verdade difere de saber a verdade, e ainda assim enganar ou omitir deliberadamente aquilo que se sabe. Se Frankfurt estiver correto, a vida cognitiva dos agentes é seriamente afetada diariamente por atitudes viciosas, por viver em um ambiente onde o descaso pela verdade é altamente difundido, ambiente cognitivamente hostil.

O descaso epistêmico é apenas um dos vícios estudados na epistemologia dos vícios, há muitos outros. Ainda que não se tenha uma lista exaustiva com os diversos vícios intelectuais, algo é certo: houve uma grande preocupação com as virtudes epistêmicas na epistemologia recente, enquanto que os vícios epistêmicos obtiveram uma atenção muito menor. Com 
intuito de ocupar essa lacuna, Cassam apresentou em seu artigo "Vice Epistemology" (2016) e posteriormente no livro Vices of the Mind (2019) o que considera serem os aspectos centrais da epistemologia dos vícios. Ao desenvolver sua proposta, Cassam opõe-se a algumas teses específicas: (i) que os traços de caráter intelectual são adquiridos; (ii) que os vícios epistêmicos possuem fundamentalmente um componente motivacional e (iii) que os vícios são qualidades profundas e duradouras que definem a identidade de uma pessoa. Segundo ele, todos estes pontos podem ser questionados. Inicialmente, os traços de caráter são adquiridos, e constituem os indivíduos. Ser um aspecto constitutivo, no entanto, não implica que não podem ser modificados. Uma pessoa mente-fechada, ainda que mantenha uma atitude dogmática frente as opiniões de outras pessoas, pode, certamente, rever suas atitudes. Em muitos casos, a pessoa dogmática não irá fazer isso. Mas é uma possibilidade disponível. Adicionalmente, Cassam sustenta a ideia de que nem sempre os vícios resultam de motivações. Uma pessoa mente-fechada e ignorante, por exemplo, tende a manter opiniões firmes. Não se pode afirmar que alguém deseja a ignorância. Ocorre simplesmente que esta pessoa não possui certos tipos de conhecimento. Um aspecto adicional de sua proposta é o consequencialismo epistêmico. Como ele afirma: "A ênfase no obstrucionismo está nas consequências dos vícios epistêmicos para nosso conhecimento ao invés dos motivos" (CASSAM, 2019, p. 5). Similar ao consequencialismo em ética normativa, o consequencialismo epistêmico atenta para as consequências da nossa performance epistêmica, em particular, as negativas.

Ainda que a epistemologia do inquérito difira das abordagens tradicionais, centradas na análise conceitual, pode-se afirmar que ela abarca diferentes concepções de conhecimento. Segundo Cassam (2019, p. 10) o obstrucionismo: "assume que o conhecimento requer crença verdadeira: se $p$ é uma proposição que somente um número pequeno de tropas seria necessário para subjugar o Iraque, então Rumsfeld conhecia que $p$ somente se $p$ fosse verdadeira". Esta noção de conhecimento admite que as pessoas comumente sabem diversas coisas, mesmo que não estejam especialmente confiantes nelas" (WILLIAMSON, 2009, p. 297). Neste sentido, é necessá- 
rio um grau de confiança mínimo naquilo que se acredita, confiança suficiente para guiar a ação.

$\mathrm{Na}$ epistemologia dos vícios um dos exemplos paradigmáticos mencionados por Cassam foi a decisão de invadir o Iraque, no qual a cúpula do governo americano, que incluía o secretário de defesa Donald Rumsfeld, o presidente George Bush, o vice-secretário de Defesa Paul Wolfowitz e vicepresidente Dick Cheney pensavam, antes da invasão, que a incursão dos soldados americanos encontraria pouca resistência por parte dos iraquianos. Segundo os relatórios da corporação RAND, esta cúpula tomou a decisão de invadir com uma quantidade de tropas muito inferior ao que era recomendado por autoridades militares, especialistas em conflitos armados ${ }^{3}$. Enviou-se 40.000 tropas ao Iraque, quando as indicações dos militares especialistas era algo em torno de 300.000 tropas. Na análise de Thomas Ricks (2006), a decisão ocorreu devido a teimosia, arrogância e a inabilidade da cúpula ao lidar com erros. Caso tivessem atentado para os indícios dos especialistas, talvez a avaliação da dificuldade do combate, e das exigências mínimas para entrar em um conflito armado fosse outra. No mínimo, evitaria o julgamento precipitado. Se observamos o que ocorreu depois, iremos notar que o conflito armado foi prorrogado desnecessariamente devido ao erro da decisão inicial, o que indica claramente as consequências negativas resultante da decisão.

Por fim, uma última característica do obstrucionismo que merece destaque, é o caráter heterogêneo dado aos vícios intelectuais. Cassam argumenta não há um aspecto fundamental que identifique os vícios intelectuais, isto é, que seja prioritário na explicação (CASSAM, 2019, p. 12). Em vez disso, o que se observa é uma diversidade de vícios operando em conjunto. Cassam destaca este aspecto da seguinte forma:

\footnotetext{
"Esta proposta de conhecimento significa que há diferentes formas para os vícios epistêmicos atrapalharem a obtenção de conhecimento. [...] Um investigador arrogante e mente fechada tende a terminar com crenças falsas do que um investigador humilde e mente aberta, e esta é uma razão para categorizar o primeiro par como vícios epistêmicos e os últimos como um par de virtudes epistêmicas" (CASSAM, 2019, p. 11)
}

\footnotetext{
${ }^{3}$ Uma análise detalhada do fiasco que foi a invasão americana pode ser encontrada em (RICKS, 2006).
} 
Em uma acepção mínima, os traços de caráter são disposições estáveis que os agentes exibem. Estas são diversas formas de os vícios impedirem a obtenção de conhecimento. Por exemplo, uma pessoa arrogante tende a agir de maneira arrogante. Irá tomar, em boa parte dos casos, sua opinião como superior. Quando em contato com a opinião de outras pessoas, tenderá a desconsiderá-las com grande facilidade. Da mesma forma, uma pessoa dogmática será firme frente a perspectivas contrárias, evitando informações que contradigam o que acredita, ou quando em contato com estas informações, irá abandona-las rapidamente.

Na classificação de Cassam (2019, p. 11), os traços de caráter são os aspectos mais rígidos dos agentes. São características que o definem o quanto pensador, adquiridas durante seu desenvolvimento. Apesar disso, são passíveis de modificação. Além dos traços de caráter, os vícios intelectuais podem ser explicados a partir das atitudes. As atitudes são orientações ou posturas em relação a algo. Por exemplo, atitudes arrogantes irão envolver modos pensar que podem ser caracterizados como arrogantes. Em uma análise mais profunda, pode-se falar inclusive em pessoas arrogantes, cujos traços são definidos, em grande medida, por estas atitudes. Neste sentido, uma pessoa pode exibir atitudes arrogantes sem ser ela mesma uma pessoa arrogante. A arrogância, compreendida desta forma, é um vício que pode ser pensado em uma destas categorias mencionadas, como um traço de caráter e enquanto atitude. A preferência por uma explicação ou outra irá depender do contexto e da recorrência das atitudes viciosas. Por fím, além dos traços de caráter e das atitudes, há os modos de pensar. Não se tratam exatamente de disposições para agir, pensar ou sentir de um modo particular. Segundo Cassam, o pensamento ilusório (whishful thinking) é um exemplo de vicio intelectual incluso nesta categoria. O pensamento ilusório resulta do que a pessoa faz em vez daquilo do que ela é. Diz respeito aos desejos do agente, que acabam tendo uma influência maior que as eventuais evidências e considerações lógicas ${ }^{4}$. Pode-se argumentar, certamente, que as ações ou atitudes nos permitem avaliar o que a pessoa é, ou seja, a pessoa é definida a partir de conjunto de suas atitudes.

\footnotetext{
${ }^{4}$ Agradeço a um revisor anônimo por destacar este ponto.
} 
Essa divisão entre traços de caráter, atitudes e modos de pensar certamente não é estanque. Busca mapear origens distintas dos vícios intelectuais, entendendo-os como mais ou menos básicos. Como ele argumenta: "Um traço $\mathrm{X}$ é mais básico que outro traço $\mathrm{Y}$ se $\mathrm{X}$ pode ser explicado sem referência a $Y$, mas $Y$ não pode ser explicado sem referência a $X$. Neste caso, $X$ é explicativamente mais básico que Y" (CASSAM, 2019, p. 14). Nesta acepção, alguns modos de pensar podem ser mais básicos que os traços de caráter, caso expliquemos os traços de caráter de alguém através dos seus diferentes modos de pensar.

O obstrucionismo apresenta algumas características importantes que nos permitem explicar os diferentes vícios intelectuais. No entanto, há propostas rivais. Uma delas sustenta que as atitudes viciosas possuem motivações não-instrumentais. Irei avalia-la na próxima seção.

\section{Motivações}

Apresentei na seção anterior o obstrucionismo. Mencionei, adicionalmente, que os vícios intelectuais são melhor compreendidos de maneira heterogênea, ou seja, não são redutíveis a um aspecto central. Incluem, além dos traços de caráter, modos de pensar e atitudes. Estas qualidades segundo o obstrucionismo, prejudicam sistematicamente as investigações nas quais estamos envolvidos. Indivíduos mente-fechada, dogmáticos e crédulos falham ao tentar adquirir e reter conhecimento, e em muitos casos tendem a acreditar em teorias conspiratórias. Uma pessoa dogmática pode, eventualmente, ter crenças verdadeiras. Mas devido as atitudes viciosas que exibe, sua performance epistêmica será afetada de forma substancial.

O obstrucionismo concorre com propostas que descrevem os vícios de uma maneira diferente. Segundo uma linha alternativa, pode-se identificar motivações não-instrumentais em casos dos vícios intelectuais (TANESINI, 2018). Ela aponta as vantagens de sua proposta do seguinte modo:

"Primeiramente, a proposta fornece uma explicação do que torna os vícios maus e por conseguinte embasa a crítica direcionada àqueles que possuem estas características. Os vícios irão derivar seu valor negativo do seu componente motivacional. Em segundo lugar, a proposta oferece um critério para a individuação dos vícios individuais, já que cada um deles possui diferentes motivações. 
Terceiro, nos ajuda a distinguir vícios de outros tipos de limitações intelectuais, como a incapacidade, cognição defeituosa, e a falta de habilidade" (TANESINI 2018, p. 8)

Esta resposta alinha-se a abordagem responsabilista das virtudes, que tomam as virtudes intelectuais como traços de caráter, características definidoras do indivíduo, e por conseguinte, passíveis de responsabilidade moral. A principal diferença entra sua abordagem e o obstrucionismo é a presença de motivos. Devido a isto, irei me deter nesta seção nos argumentos oferecidos por A. Tanesini acerca deste aspecto. Em última instância, irei sustentar que nem sempre os vícios intelectuais envolvem motivos para se opor aos bens epistêmicos, ainda que em muitos casos possamos identificar motivações.

$\mathrm{O}$ argumento central de Tanesini baseia-se na distinção entre razões que motivam e razões que explicam. Irei me deter nesta distinção mais adiante. Antes, irei detalhar mais alguns esclarecimentos sobre a natureza dos vícios. Retomando a definição, os vícios intelectuais são caracterizados negativamente, ou seja, consistem em obstáculos a obtenção e manutenção de conhecimento. Assim como Cassam, Tanesini considera os vícios disposições mais ou menos estáveis que os agentes exibem. Estas disposições podem ser observadas a partir das atitudes que os agentes adotam. Uma pessoa preconceituosa tende a tomar atitudes preconceituosas. Da mesma forma, uma pessoa arrogante tende a tomar atitudes arrogantes. Estas atitudes seriam como preferências contra ou a favor de algum objeto. A atitude de alguém perante um grupo social ou um partido político. Positivamente, a pessoa pode gostar de um grupo social que se reúne para jogar vôlei ou futebol, assim como alinhar-se a um partido político. Contrariamente, pode não gostar deste mesmo grupo social e ter uma atitude negativa com relação a um partido político. Segundo a concepção de Tanesini, nos casos dos vícios intelectuais, estas atitudes são adquiridas ou mantidas a serviço de objetivos como defender seu ego ou expressar valores. Em uma palavra, motivos. Ela encerra na definição de vicio intelectual a ideia de que os motivos são uma característica fundamental. Um caso que considera em suporte desta perspectiva motivacional é o da malevolência epistêmica, que consiste na oposição aos bem epistêmicos, em suas diversas encarnações (BAEHR, 2010, 
192). Uma pessoa epistemicamente malevolente irá antagonizar, bloquear ou prevenir aquilo que ele considerar epistemicamente boa, criando obstáculos na aquisição deste bem. Este bloqueio pode ser direcionado a uma pessoa específica ou ao bem epistêmico em si. Um dos exemplos mencionados por Baehr (2010) é retirado da autobiografia de Frederick Douglass. A personagem Sophia Auld, após ensinar Douglass a ler, torna-se uma pessoa epistemicamente malevolente, influenciando seu marido de forma que ele não progrida em seus estudos. Ela responde de maneira agressiva as tentativas de Douglass obter conhecimento. Em um caso análogo, pode-se pensar em uma pessoa arrogante que impede ou limita a obtenção de conhecimento de outra pessoa por se considerar superior. Esta pessoa bloqueia o acesso aos bens epistêmicos a outra, mas não é, necessariamente, alguém epistemicamente malevolente. Nesta acepção, a malevolência epistêmica difere da arrogância intelectual, ainda que ambas atitudes de oposição a bens epistêmicos.

Tanesini apresenta diversos casos com intuito de demonstrar a plausibilidade da proposta centrada nas motivações. O primeiro caso discutido é o da preguiça intelectual exibida por Oblomov, a personagem principal na novela de Goncharov. Segundo Crerar (2018), Oblomov que não possui motivação ou interesse em seja o que for ${ }^{5}$. É alguém que não possui interesse cognitivo na realidade. Em uma explicação inicial, podemos afirmar que Oblomov não possuir motivações para perseguir bem epistêmicos que consideramos essenciais. Em outras palavras, não possui motivação. Aparentemente, o caso não aponta para a existência de motivações não instrumentais atuando, já que resulta de uma apatia. Um caso diferente é de um cientista chamado Galileu, que busca a verdade, mas é arrogante. Neste caso, ainda que Galileu valorize a verdade como bem epistêmico, ele tende a desconsiderar as habilidades de seus interlocutores, não dando atenção ao que dizem. Em suma, ele é uma pessoa intelectualmente viciosa. Um terceiro caso, inicialmente proposto por Cassam (2016), é de alguém chamado Oliver, que busca a verdade, mas é intelectualmente vicioso, pois acaba por acreditar em teorias falsas, em particular, teorias conspiratórias. Devido ao fato de este

\footnotetext{
${ }^{5}$ Note-se que alguns destes casos considerados aqui envolvem personagens ficcionais. Para todos os efeitos, assumo que isto não irá influenciar de maneira significativa nossa avaliação.
} 
caso ser explicado por Crerar (2018) como um caso de defeito cognitivo, Tanesini apresenta uma variação deste exemplo, chamada Olivia. Na descrição, Olivia é motivada pela verdade, mas intelectualmente viciosa. Ela tem interesse pela verdade, é curiosa e perseverante (TANESINI, 2018, p. 356). Ela deseja acreditar somente em teorias verdadeiras, mas possui um ponto cego. É mente fechada sobre suas teorias preferidas, ainda que demonstre das diversas disposições comportamentais de uma pessoa virtuosa.

Nos três casos acima Tanesini admite que há explicações alternativas ao obstrucionismo perfeitamente compatíveis com as atitudes viciosas. Seu argumento central se baseia em uma distinção comum em filosofia da ação, entre razões que motivam e razões explicativas. Tanesini, podemos dividir as explicações em três tipos: justificações, racionalizações e meras explicações (TANESINI, 2018, p. 362). No primeiro caso, explicamos uma ação ou crença a partir das justificações que levou a uma ação determinada ou que suportam uma crença particular. Estas razões são normativas, isto é, fornecem uma justificação racional para uma crença ou ação. Uma racionalização aduz razões para um agente em suporte de crenças e ações. Sabe-se que estas razões são na generalidade dos casos motivadas. $\mathrm{O}$ agente assume que elas suportam racionalmente suas ações ou crenças, ainda que em muitas situações isto não seja o caso. No caso de uma mera explicação, fornecemos razões para uma ação ou crença sem necessariamente justifica-la ou racionaliza-la. Por fim, as racionalizações e as meras explicações são explicações psicológicas, enquanto as justificações não.

Com intuito de esclarecer a distinção, ela menciona a morte de Desdemona por Otelo ${ }^{6}$. A descrição comumente feita deste caso ficcional é de que Otelo assassina Desdemona a por ciúmes. Contudo, não há justificação moral para o assassinato. No entanto, Otelo fornece diversas racionalizações. As as razões que o motivam, segundo Tanesini, são de que ela o traiu, o que se trata de uma racionalização. O que o motivou na realidade foi o ciúme, ainda que Otelo pense ser a traição o motivo principal de sua ação de matá-la. Neste sentido, a razão que o motiva não é a mesma que ele racionaliza ao explicar seu comportamento.

\footnotetext{
6 "Otelo, o Mouro de Veneza" é uma obra clássica de Shakespeare, cujo tema principal é o ciúme e as intrigas geradas por este sentimento.
} 
Para explicar o caso de Oblomov Tanesini (2019, p. 365) sustenta que sua preguiça é motivada por um vício intelectual que o leva a se afastar de bens epistêmicos. Da mesma forma, sustentando-se na distinção anterior, mantém o mesmo julgamento para os casos de Galileu e Olivia. No primeiro caso, busca-se a verdade, mas a arrogância dificulta esta obtenção. No caso de Olivia, ainda que ela valorize a verdade, sua atitude viciosa de ignorar evidências contrárias à sua posição. Esta disposição para ignorar evidências contrárias à sua posição consiste em motivos para se opor a bens epistêmicos. Neste sentido, Olivia é uma pessoa dogmática.

Todos estes casos apresentados podem avaliados a partir da distinção entre razões explicativas e racionalizações, o que suportam a presença de motivações em casos de vícios intelectuais. A prática de atribuir responsabilidade, segundo Tanesini, está no centro da discussão, e por isso deve ser levado em conta. No entanto, será que esta distinção entre razões que motivam e razões explicativas se sustenta? Isto é, será que ela nos permite inferir a presença de motivos em todas as ocorrências de vícios? Se a distinção mantida por ela não levar a inferência de que todos os casos de vícios intelectuais possuem motivações, então bloqueia-se o argumento.

Uma primeira qualificação que pode ser feita é indicar com Cassam que mesmo admitindo boas motivações nas diversos exemplos de virtudes intelectuais, daí não se segue que há motivações em todos os casos de vícios (CASSAM, 2019, p. 5). Dos casos mencionados, o da preguiça não parece resultar de uma motivação particular, mas sim da falta de motivações para seja o que for. Da mesma forma, pode-se argumentar que as pessoas mentefechada possuem um desejo pela firmeza em suas opiniões sem ter como pano de fundo uma motivação epistemicamente má. Por fim, pode-se sustentar que o preconceito também não é nem um traço de caráter nem um modo de pensar, mas uma atitude. Em suma, parece haver diversos casos de vícios intelectuais sem a presença de motivações?

\footnotetext{
${ }^{7}$ Em uma publicação mais recente Tanesini (2020) responde ao dilema que será apresentado na seção 3. Destaco ao final do texto o modo como ela compatibiliza a proposta de Cas sam como nossa prática de atribuição de responsabilidade.
} 


\section{Responsabilidade}

Após avaliar as duas propostas em epistemologia dos vícios, gostaria de me deter em um aspecto que foi considerado ao longo do texto, mas não em profundidade: até que ponto os vícios intelectuais são repreensíveis? Isto é, em que circunstâncias podemos responsabilizar a pessoa por sua atitude viciosa? Mencionei alguns exemplos onde a atribuição de responsabilidade parece incontroversa. Um deles foi a decisão do governo americano de invadir o Iraque em 2003. Segundo uma compreensão razoável do evento, a decisão resultou de uma arrogância intelectual por parte da cúpula do governo, já que antes do envio das tropas os especialistas apontaram para o erro em enviar menos tropas do que o necessário, informação que foi ignorada. No entanto, há casos onde a atribuição de responsabilidade não é tão clara. Casos envolvendo vieses implícitos oferecem uma dificuldade para a epistemologia dos vícios. Inicialmente, por envolve a relação entre valores e crenças implícitos, como os valores e crenças que mantem explicitamente. Por exemplo, casos onde uma feminista que trabalha ativamente em sua comunidade combatendo a desigualdade de gênero, mas que uma determinada circunstância adota uma injustiça testemunhal. Em casos assim, até que ponto devemos responsabilizar as pessoas por suas atitudes viciosas? Para responder esta questão, temos de primeiro caracterizar de maneira clara a natureza dos vícios intelectuais. Apresentei nas duas últimas seções as propostas mais proeminentes na literatura. Primeiro, o obstrucionismo desenvolvido por Cassam, e em seguida a abordagem motivacional de A. Tanesini, que segue uma linha responsabilista das virtudes. No primeiro caso, não se adota um componente ou aspecto como central na caracterização dos vícios, enquanto que no segundo caso afirma-se que há motivos não-instrumentais nas ocorrências dos vícios. Penso que a caracterização de Cassam nos permite compreender os diversos casos de vícios sem ter uma preocupação excessiva com a atribuição de responsabilidade, isto é, penso que tentar fornecer uma consequência da origem diversa dos vícios intelectuais nos permite afirmar que uma muitas situações o agente não tem como ser responsável pela atitude viciosa. Devido a ambiguidade quanto a natureza da culpabilidade em casos de vícios intelectuais H. Battaly (2019) argumentou recentemente que a 
epistemologia dos vícios possui um problema de responsabilidade. Ela apresenta o problema nos seguintes termos:

"A epistemologia dos vícios dedica-se a definição dos vícios epistêmicos. Um dos requerimentos propostos é que eles sejam repreensíveis, ou criticáveis, ou culpáveis de um modo não-voluntarista, mesmo quando o agente não é responsável por eles (porque ele não possui controle sobre eles). Isto nos leva a um problema de responsabilidade. Se nossa análise da responsabilidade não-voluntarista termine sendo muito restritiva, então corre-se o risco de algumas qualidades que queremos incluir entre os vícios epistêmicos serão excluídos. Por outro lado, se termine sendo muito abrangente, corre-se o risco de incluir qualidades que não queremos contabilizar como vícios epistêmicos.” (BATTALY, 2019, p. 25)

Para avaliar a natureza da responsabilização temos de considerar, principalmente, o controle por parte do agente. Uma definição de vicio intelectual deve explicar não apenas as situações em que eles são repreensíveis de uma maneira não-voluntarista, ou seja, os vícios exibidos pela pessoa não estão sob controle, mas são passíveis de responsabilização. Battaly afirma que devemos evitar que pessoas epistemicamente viciosas não sejam responsabilizadas por suas atitudes. Casos envolvendo vieses implícitos se encontram nesta categoria. Eles não estão sob nosso controle, ou possuímos apenas um controle indireto sobre eles, exigindo mudanças de longo prazo. Ao avaliar a discussão sobre a natureza dos vícios intelectuais, a dificuldade parece residir na parte "não-voluntarista" da enunciação do problema. Por definição, se trata de algo que o indivíduo não tem como controlar.

Para entender a dificuldade que é apontada por Battaly é necessário apresentar uma distinção entre um vício ser repreensível e ser culpável (CASSAM, 2019, p. 22). Os vícios culpáveis são aqueles que temos algum controle, logo somos responsáveis. Os vícios são repreensíveis quando não estão sob nosso controle, mas ainda assim afetam nossa performance epistêmica. Pessoas com problemas graves de memória, com visão limitada ou consistentemente desatentas terão suas performances epistêmicas afetadas devido a estas qualidades. As qualidades obstruem consistentemente a produção de efeitos epistêmicos bons. Apesar dos efeitos destas características, estas pessoas não são culpáveis, devido a estas disposições cognitivas não estarem sob controle. No caso das qualidades repreensíveis, há algo de ruim nelas que se pode associar a um agente, independente de ele possuir contro- 
le. Seguindo o trabalho de George Sher (2006) e Angela Smith (2008), Cassam considera dois requerimentos para um vício ser repreensível. Inicialmente, uma qualidade é repreensível quando está em um relacionamento próximo com o agente, algo que irá refletir de maneira negativa neste mesmo agente (SHER, 2006, p. 57). Os defeitos cognitivos, como ter uma visão limitada, segundo esta descrição, não está em um relacionamento próximo do agente, isto é, não refletem seus valores e crenças. Por outro lado, ser uma pessoa arrogante ou epistemicamente malevolente é algo que influencia diretamente na agência epistêmica do indivíduo. Por esta razão, criticar a atitude de alguém é algo que não se separa de uma crítica a esta pessoa específica (CASSAM, 2019, p. 23). Estas qualidades são profundas, e por conseguinte, passíveis de responsabilização. Qualidades profundas são definidoras de alguém como pensador. Uma pessoa arrogante irá desenvolver suas investigações de modo a pensar que seu julgamento é no geral melhor do que a de seus pares. Por outro lado, a visão limitada de alguém não o define enquanto pensador.

Uma outra distinção que nos permite considerar o problema da responsabilidade em mais detalhe, é entre vícios que somos responsáveis por sua aquisição e vícios para os quais somos responsáveis por sua revisão ou mudança. Temos responsabilidade pela aquisição de um vício $\mathrm{V}$ quando nossas ações, omissões, escolhas e decisões passadas resultaram na sua aquisição ou desenvolvimento (CASSAM, 2019, p. 124). Os vícios pelos quais somos responsáveis por sua revisão, por outro lado, diferem daqueles adquiridos. Basta pensarmos no caso dos recrutas do Talibã. A atitude dogmática deles se deve em parte a sua criação e desenvolvimento; resulta do ambiente no qual estão inseridos. Neste caso, eles não são responsáveis pela aquisição de vícios como o dogmatismo, ainda que sejam responsáveis por sua revisão. Sendo assim, mesmo que não sejamos responsáveis pela aquisição de um determinado vício intelectual, temos a responsabilidade de o revisar. Algumas destas atitudes viciosas, em boa parte dos casos, foram adquiridas na juventude, período em que as capacidades cognitivas estão em desenvolvimento, e a maturidade e sofisticação para julgar certos tipos de doutrinação ainda não foram atingidos. Por outro lado, se admitirmos que mudanças de atitude estão ao alcance da generalidade das pessoas, então de- 
vemos reconhecer, ainda que parcialmente, a atribuição de responsabilidade. Como dito anteriormente, temos um controle indireto. Uma mudança em direção a aceitação de ideias e a abertura de espírito representam um ganho, ainda que muitas pessoas não se disponham a revisão de suas ideias.

Battaly, com intuito de destacar o problema da responsabilidade, questiona a distinção entre vícios culpáveis e repreensíveis, e apresenta um caso que supostamente não seria abarcado pela distinção. $\mathrm{O}$ caso foi inicialmente proposto por M. Fricker (2007), e trata-se de uma feminista com viés implícito. Neste caso descrito por Fricker, uma feminista apresenta um testemunho injusto. A injustiça epistêmica ocorre quando, em contextos assertivos, desconsidera-se ou rejeita-se a palavra de outra pessoa devido a suas preferências sexuais, etnia ou raça. Esta injustiça testemunhal tem a forma de um preconceito perceptual que opera em um nível abaixo do da crença e dos motivos, sem a permissão do agente (FRICKER, 2007, p. 39). A ação da feminista, ao praticar esta injustiça testemunhal, não reflete seus valores e motivos, mas operam contrários a eles. Segundo Battaly este caso seria um contra exemplo ao obstrucionismo. $\mathrm{O}$ argumento tem o formato de um dilema: "o obstrucionismo está comprometido com as seguintes afirmações: ou (i) alguns vícios epistêmicos são culpáveis sem serem repreensíveis, ou [...] (ii) o agente será repreensível por seus defeitos cognitivos" (BATTALY, 2019, p. 29). No caso da feminista, admite-se que os vieses implícitos são vícios epistêmicos. Ademais, na concepção de Cassam somos responsáveis pela revisão das atitudes viciosas, mas raramente responsáveis por sua aquisição. Por esta razão, se a feminista não for repreensível por sua injustiça testemunhal, isto significa que sua atitude preconceituosa não reflete de maneira negativa nela. Neste sentido, o vício resulta principalmente da comunidade na qual ela foi criada e está inserida. Para refletir de maneira negativa, esta atitude deveria envolver aspectos de sua agência epistêmica próximos ao seu self, a saber, suas crenças e valores. Contudo, são justamente suas crenças e valores que são suplantados pela atitude viciosa. Parece ser o caso que sua atitude viciosa não resulta dos valores que a definem. $\mathrm{O}$ resultado contraintuitivo deste caso é que a feminista é responsável pela revisão de sua injustiça testemunhal ainda que não seja repreensível, nesta suposição. Expandindo o argumento, temos que (BATTALY, 2019, p. 30): 
"1. A injustiça testemunhal da feminista é um vício epistêmico.

2. De acordo com o obstrucionismo, um agente irá ou ser responsável pela aquisição ou responsável por sua revisão, ou repreensível por seus vícios epistêmicos.

3. A feminista não é responsável pela aquisição de sua injustiça testemunhal.

4. Ela é ou não é repreensível por sua injustiça testemunhal.

5. Se ela não é repreensível por sua injustiça testemunhal, então ela é responsável por sua revisão.

6. Se ela é responsável pela revisão, então ela é culpável.

7. Mas, então sua injustiça testemunhal é um vício epistêmico que é culpável sem ser repreensível.

8. Se, por outro lado, ela é repreensível por sua injustiça testemunhal, então ela é repreensível por seus defeitos cognitivos."

Admitindo a existência do problema, quais as possibilidades de resposta? Battaly menciona duas. Uma, é admitir o pluralismo, e sustentar que os vícios possuem diferentes origens e que em alguns casos eles não são passíveis de responsabilidade ou repreensíveis. Ela recusa essa resposta e propõe uma via que parte da análise de Sher (2006), segundo a qual o agente é responsável por aquelas qualidades que estão próximas do seu self, e refletem de maneira negativa em si. Este ponto de partida, segundo ela, não nos leva a uma análise muito restritiva, no entanto, corre o risco de ser abrangente demais, incluindo características como a visão limitada.

Uma outra forma de responder ao dilema consiste em afirmar que os vieses implícitos são como a visão limitada, efeitos-vícios (effect-vices), isto é, eles geram efeitos epistemicamente maus sem necessariamente serem passíveis de responsabilização. Em outra publicação, Battaly admite que esta é uma possibilidade disponível (BATTALY, 2017). Apesar disso, ela se mostra insatisfeita com ambas as alternativas e propõe que a epistemologia possui um problema de responsabilidade.

Com intuito de dar conta deste dilema, e com a heterogeneidade dos vícios, em um texto recente Tanesini $(2020$, p. 7) recomenda uma solução disjuntiva, na qual:

"Nós podemos fornecer uma explicação de porque quando nós atribuímos vício a alguém nós estamos realizando no mínimo duas coisas: culpando a pessoa pelo vício e/ou mostrando nosso desdém ou desaprovação pelo que a pessoa é”. Ainda que programática, sua explicação busca classificar os vícios a partir das reações que temos para quem os exibe. Estas reações reativas, por sua vez, envolvem: "ressentimento, admiração, gratidão, e raiva direcionada a outros pelo que ela são e fizeram" (TANESINI, 2020, p. 7) 
Nesta acepção, a atribuição de responsabilidade tem relação direta com o modo como reagimos as diferentes atitudes viciosas. As diferentes reações que temos ao comportamento das pessoas, e por conseguinte, os diferentes modos de responsabilização, estão sujeitas ao erro. Com intuito de acomodar esta ambiguidade na atribuição de responsabilidade, Tanesini apresenta uma distinção adicional entre tipos de responsabilidade:

\begin{abstract}
"A primeira face é a responsabilidade de atribuição. [...] que o indivíduo tem por seu caráter ou self profundo. [...] A segunda face é a responsabilidade de resposta. É o tipo de responsabilidade atribuída a pessoas quando demandamos delas respostas por suas crenças e conduta através de razões para justifica-las. [...] A terceira face é a responsabilidade atribuída a pessoas quando esperamos delas algum reparo menor. Expressamos esta resposta através da raiva para indicar [...] a falta de consideração com nosso ponto de vista" (TANESINI, 2020, p. 8-9)
\end{abstract}

Esta nova classificação busca dar conta dos diferentes cenários em que há atribuição de responsabilidade, os quais tem como função identificar os aspectos negativos dos vícios intelectuais através de nossa desaprovação. Segundo ela, com esta nova classificação a explicação fornecida por Cassam não sofre modificações substanciais e nos permite dar sentido a atribuição de responsabilidade nos diversos casos de vícios intelectuais.

\title{
5. Considerações Finais
}

Neste trabalho apresentei duas propostas sobre a epistemologia dos vícios. Inicialmente, detalhei os argumentos a favor do obstrucionismo. O obstrucionismo sustenta que os vícios intelectuais são traços de caráter, atitudes ou modos de pensar que se interpõem, limitam, dificultam ou impede a obtenção do conhecimento. Nesta primeira proposta, não há uma tentativa de redução dos vícios intelectuais a uma categoria fundamental. Mantém-se uma abordagem pluralista. Em seguida, considerei a proposta alternativa de A. Tanesini. Segundo ela, os vícios intelectuais trazem consigo motivações não-instrumentais para se opor a bens epistêmico. Segundo seu argumento, a distinção entre razões explicativas e razões que motivam nos permite identificar estas motivações. Após considerar os diversos exemplos presentes na literatura, sustentei que nem todos os vícios intelectuais possuem motiva- 
ções subjacentes. Por fim, avalie o problema da responsabilidade levantado por H. Battaly, indicando ele pode ser acomodado pelo obstrucionismo .

\section{Referências}

AXTELL, Guy. Knowledge, Belief, and Character. Lanham, Rowman and Littlefield, 2000.

BAEHR, Jason. "Epistemic Malevolence”. Metaphilosophy, v. 41, Issue 1-2, 2010, p. 189-213.

BATTALY, Heather. (2019). "Vice epistemology has a responsibility problem”. Philosophical Issues, v. 29, Issue 1, 2019, p. 24-36.

. "Testimonial injustice, epistemic vice, and vice epistemology". In I.

J. Kidd, G. Polhaus, \& J. Medina (Eds.), The Routledge handbook of epistemic injustice (pp. 223-231). New York: Routledge, 2017.

CASSAM, Quassim. "Vice Epistemology”. The Monist, n. 99, 2016, p. 159180.

. "Epistemic Insouciance". Journal of Philosophical Research. v. 43, 2018, p. 1-20.

. Vices of the Mind: from the Intellectual to the Political. Oxford: Oxford University Press, 2019.

CRERAR, Charlie. "Motivational approaches to intellectual vice". Australasian Journal of Philosophy, v. 96, 2018, p. 753-766.

FRANKFURT, Harry. On Bullshit. Princeton, NJ: Princeton University Press, 2005.

FRICKER, Miranda. Epistemic Injustice: Power and the Ethics of Knowing. Oxford: Oxford University Press, 2007.

SHER, George. In praise of blame. Oxford: Oxford University Press, 2006.

SMITH, Angela S. "Control, responsibility, and moral assessment". Philosophical Studies, v. 138, 2008, p. 367-392.

SOSA, Ernest. A Virtue Epistemology: Apt Belief and Reflective Knowledge, Vol. I. New York: Oxford University Press, 2007.

Reflective Knowledge: Apt Belief and Reflective Knowledge, Vol. II. New York: Oxford University Press, 2011.

\footnotetext{
${ }^{8}$ Gostaria de agradecer as discussões online no grupo de epistemologia da UFSC, e ao revisor anônimo pelas correções e indicações recomendadas, elas foram de grande ajuda.
} 
TANESINI, Alessandra. "Epistemic Vice and Motivation". Metaphilosophy, v. 49,2018 , p. 350-367.

- "Blaming the Intellectually Vicious: a Critical Discussion of Cassam's Account of Blameworthiness and Reprehensibility for Epistemic Vice". Ethical Theory and Moral Practice, 2020.

RICKS, Thomas E. Fiasco: The American Military Adventure in Iraq. Penguin Press, New York, 2006.

ROBERTS, ROBERT C.;WOOD, W. JAY. Intellectual Virtues: An Essay in Regulative Epistemology. Oxford: Oxford University Press, 2007.

WILLIAMSON, T. "Reply to Elizabeth Fricker". In P. Greenough and D. Pritchard (eds), Williamson on Knowledge. Oxford: Oxford University Press, 2009.

ZAGZEBSKI, Linda. Virtues of the Mind: An Inquiry into the Nature of Virtue and the Ethical Foundations of Knowledge. Cambridge: Cambridge University Press, 1996. 